\title{
Non-invasive, real time in-situ techniques to determine the ripening stage of banana
}

\author{
Tilman Ringer ${ }^{1} \cdot$ Michael Blanke $^{1}[0$
}

Received: 20 August 2020 / Accepted: 13 June 2021 / Published online: 19 June 2021

(c) The Author(s) 2021

\begin{abstract}
Bananas were examined starting from ripening stage R2 (green) to stage R7 (overripe), to identify suitable non-invasive, real time in-situ technologies to separate the ripening stages: (1) Chlorophyll degradation, measured by the DA meter, decreased from ca. 2.1 (R2) to 0.2 IAD units (R7), i.e. tenfold decline. (2) Colour CIE-Lab a values dramatically increased as indication of chlorophyll breakdown and enable differentiation between all ripening stages R2 to R7. Colour angles declined from $98.7^{\circ}$

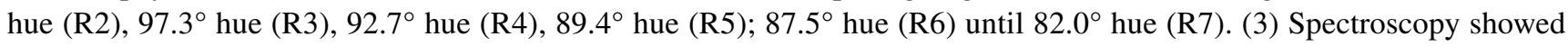
two light reflectance troughs at $494 \mathrm{~nm}$ and $679 \mathrm{~nm}$. A novel banana ripening index (BRI) was developed and is proposed to identify and distinguish the ripening stages of banana with values starting at 4 at $R 1$ and peaking at 8.1 at ripening stage R7. (4) Peel gloss increased from stage R2 (150 a.u.) to stage R7 (220 a.u.) in the order of ca. 50\% followed by a subsequent decrease thereafter. (5) Peel softening declined as fruit firmness dropped from 82 Shore at stage R2 to 42 Shore at stage R7 (overripe), measured also at the centre of the banana fruit. (6) After a constant 90.5\% water content per fresh mass (FM) in the banana peel until stage R5, the subsequent drop to $82.9 \% \mathrm{FM}$ at R7 and 7.6\% water translocation viz displacement from the peel to pulp explained this softening. All the above results identified the fruit centre (rather than the tip) as a suitable candidate due to the most advanced ripening and least curved surface region of the fruit with easy access, when a carton is opened and the hands become accessible. This novel approach based on a comparison has shown the DA-meter, colorimeter and spectrometer as suitable candidates for the identification of each ripening stage. The combination of these three devices may be suitable for monitoring of banana ripening rooms in terms of temperature and humidity in addition to the present, colour-based ripening scale.
\end{abstract}

Keyword Banana (Musa sapientum) $\cdot$ Chlorophyll degradation $\cdot$ Colour $\cdot$ DA-meter $\cdot$ Glossiness $\cdot$ Non-invasive measurement $\cdot$ Precision horticulture $\cdot$ Ripening $\cdot$ Spectral index $\cdot$ Water displacement

\section{Introduction}

Non-invasive measurement technologies are becoming more suitable for the fruit industry because of the possibility to analyse the fruit without destroying the peel in a box onboard during shipment, before entering a ripening room or thereafter to predict shelf life [1]. After harvest, it is indispensable to parametrise the identification of fruit maturation and, in banana, the particular ripening stage and the optimum ripening treatment.

Michael Blanke

mmblanke@uni-bonn.de

1 INRES-Horticultural Science, Auf dem Hügel 6, 53121 Bonn, Germany
Ripening of dessert banana (Musa sapientum) as a climacteric fruit, which implies ripening continues after harvest [2] is associated with biochemical and physical changes. Banana ripening comprises a change in colour from green to yellow starting from the centre of the banana fruit and then extending to its tips. Because the colour varies from the centre of the banana fruit to the tips, many positions on the banana peel had to be measured to create a representative colour profile [3]. Ripening of bananas is also associated with softening and change in surface features. The reports on the change in physical properties started 20 years ago using a destructive method, i.e. relied on measurements with fruit after peeling [4].

Recently, a new generation of sensor technology has been introduced. Two devices, the luster sensor technology [5] and a new device (DA Meter) [1], seem suitable 
for banana in addition to colourimeter, spectroscopy, penetrometer, the iodine starch test and water displacement.

The scientific challenge is to investigate, which of these six old and new technologies are most suitable to exactly identify the particular banana ripening stage and offer the professional ripening industry support in form of parameters. Pre-requisites are non-invasive, on-site and real-time methods without destruction of the fruit, and without sampling for laborious laboratory analysis. Hence, the objective of the present project is to compare predominantly non-invasive, real time, on-site and affordable technologies as to their suitability to identify the ripeness stage of banana either during or before entering the ripening room or in retail or both.

Therefore, biophysical and biochemical changes were examined during banana ripening at their final destination in the food chain by mostly non-invasive techniques: a luster sensor, colourimetry, spectrometer, DA-meter for chlorophyll degradation, water movement, starch index and a penetrometer.

\section{Material and methods}

\section{Fruit source}

Dessert bananas (Musa sapientum) of all maturity stages (Fig. 1) were obtained and their characteristics followed during ripening. Immature banana fruit of maturity stage $\mathrm{R} 2$ came fresh from shipments before entering the ripening room, while for the following ripening stages pre-ripened bananas of stage $\mathrm{R} 3$ until ripening stage $\mathrm{R} 7$ and thereafter (overripe) were investigated. The fruit were collected from our local banana ripening company (Walter Pott Ltd., Leverkusen, Germany, ca. $50 \mathrm{~km}$ from Bonn), which supplies ripened fruit to the local supermarket Norma in Bonn as our source for ripe fruit.

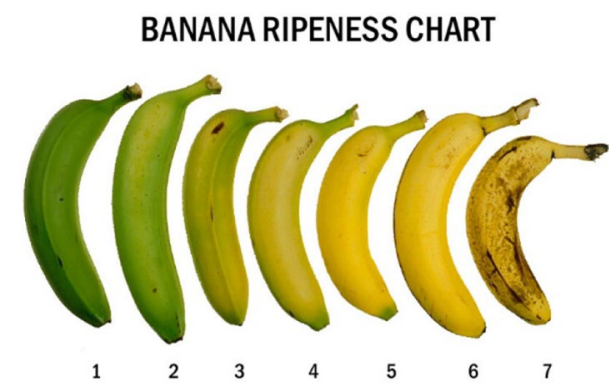

Fig. 1 Banana ripening scale. Don Edwards, UC Davis, Postharvest, California, USA (Color figure online)

\section{Measuring position}

The fruit surface was examined on the tip and centre/middle straight part of the bananas. These spots were marked as previously described by Ringer et al. [5] and the same spots employed for replicate measurements of glossiness, colour and chlorophyll degradation. At each ripening stage, 15 fingers were removed off banana hands from fresh shipments. For each banana, four measurements were conducted, two at the tip (20 mm from the blossom end) and two in the middle of the fruit. The tip was included as measuring spot, because it turns colour from green to yellow much later than the centre part. All measurements were taken perpendicular to the longitudinal axis of the banana in real time, in-situ, without need to send in to the laboratory.

\section{Instrumentation: glossiness}

The non-invasive, real-time gloss measurement employed a luster sensor type CZ-H72 and amplifier (Keyence Co., Osake, Japan) operated at $14.8 \mathrm{~V}$. The distance between the banana surface and sensor was kept constant at $15 \mathrm{~mm}$ by our own manufactured holder with the spot size set to $5 \mathrm{~mm}$ [5]. The LED of the sensor emits red light at $665 \mathrm{~nm}$, and the detector measures the reflected light.

\section{DA- meter}

Chlorophyll degradation in the banana peel was measured non-invasively in-situ and real time by selective disappearance of the green colour using the portable battery-driven DA Meter (Turoni Instruments, Bologna, Italy). Its index of absorption difference $\left(\mathrm{I}_{\mathrm{AD}}\right)$ describes the difference in light reflection between the chlorophyll specific wavelength $(670 \mathrm{~nm})$ and a NIR wavelength $(720 \mathrm{~nm})$ as reference [6], $720 \mathrm{~nm}$ is at the start of the NIR, where light reflection from biological material such as leaves and fruit increases.

\section{Colourimetry}

The surface colour of the banana fruit was measured at the tip and centre part with a non-invasive, portable colourimeter (380-720 nm) using an i1Pro (X-Rite, Michigan, USA) (Fig. 2) with a resolution of $10 \mathrm{~nm}$ and a measuring spot size of $3.5 \mathrm{~mm}$ diameter (Table 1). The output of the device, i.e. colour values L (brightness), a (red to green) and b (yellow to blue) [7] in die CIE-Lab colour space, was converted to ${ }^{\circ}$ hue colour angle according to McGuire [8] (and colour saturation chroma). 
Fig. 2 Colour measurements in the centre of the banana fruit (left) and spot size (right) (Color figure online)

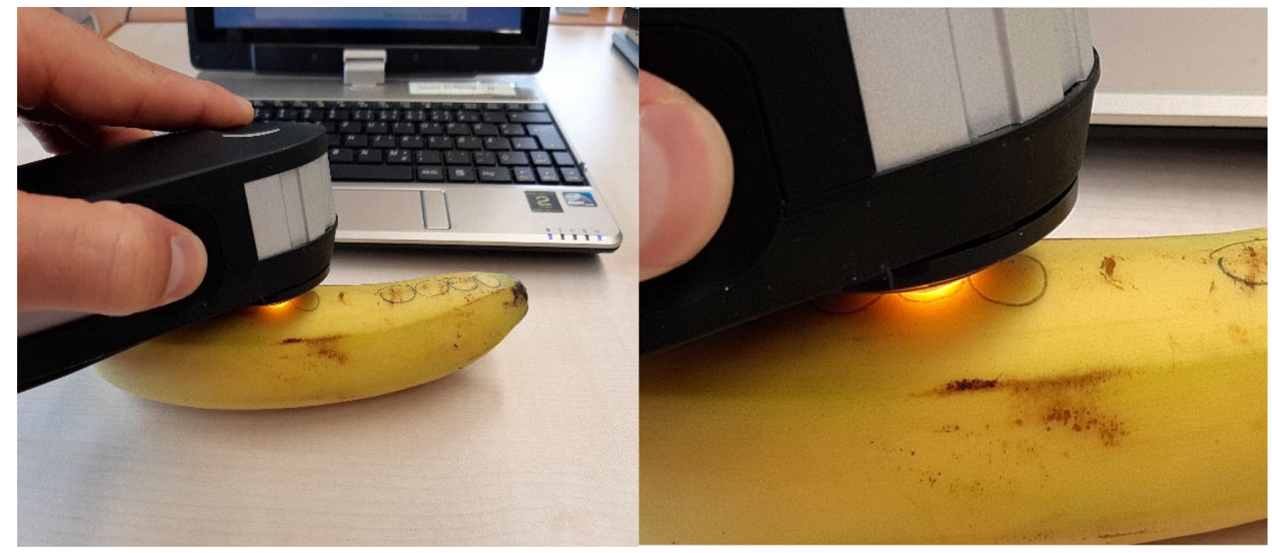

Table 1 Technical specification of the non-invasive real-time instrumentation employed for maturity of banana fruit

\begin{tabular}{|c|c|c|c|}
\hline Method & Parameter & Resolution & $\begin{array}{l}\text { Spot size/ } \\
\text { test anvil } \\
\text { size }\end{array}$ \\
\hline Luster sensor & Glossiness & n.a & $5 \mathrm{~mm}$ \\
\hline DA Meter & $\begin{array}{l}\text { Chlorophyll } \\
\text { degradation }\end{array}$ & 0.1 & $7 \mathrm{~mm}$ \\
\hline Colourimeter & Colour & $10 \mathrm{~nm}$ & $3.5 \mathrm{~mm}$ \\
\hline Spectrometer & Reflection & $0.5 \mathrm{~nm}$ & $2 \mathrm{~mm}$ \\
\hline Penetrometer & Firmness & $0-100$ shore & $0.5 \mathrm{~cm}^{2}$ \\
\hline
\end{tabular}

\section{Spectrometry}

Spectral reflection of the banana peel was measured in real time and non-invasively by a spectrometer (Stellar Net Inc., Florida, USA) using a 'BLUE wave box' and a SL1 light source $(190-1100 \mathrm{~nm})$ with a resolution of $0.2-6.0 \mathrm{~nm}$ depending on wavelength and a flexible glass fibre cable to provide a measuring spot of $2 \mathrm{~mm}$ average with a measuring time of less than $1 \mathrm{~s}$ following Schüsseler et al. [9]. Reflection values were processed using the software 'SpectraWiz Shortcut' supplied as part of the package. Spectra in Fig. 6 are presented as original graphs after division by the white calibration curve. This was obtained by setting the reflection from the supplied white barium sulphate as $100 \%$ reflection (Fig. 2).

\section{Starch index, firmness, fresh and dry mass and water relocation}

Banana fruit of each ripening stage were halved perpendicular. Both cross sections with 5 replicates were stained with potassium iodine to visualise the changes in starch distribution, i.e. degradation in accordance with the Streif index for apples.
Firmness of attached banana peel was measured at the centre of the fruit at the different ripening stages using a firmness tester penetrometer HP II Fff (Bareiss, Oberdischingen, Germany), otherwise used for other fruit with values expressed as Shore values.

Fresh mass was determined of the complete fruit, the separated flesh and peel. These fruit sections were dried in an oven at $60^{\circ} \mathrm{C}$ until the weight was constant to determine their dry mass. The water translocation was calculated from the difference between the water content from the peel and the pulp over time. Values were then corrected for transpirational water loss i.e. weight loss of the whole intact fruit, assessed concomitantly.

\section{Statistics}

After testing for normal distribution (Kolmogorov-SmirnovTest and Shapiro-Wilk test) and for variance homogeneity (Levene test). Data for Figs. 3 and 4 were subjected to a onefactorial analysis of variance (ANOVA) or the Welch test (in case of variance heterogeneity) and the Tukey-test using SPSS version 24 (IBM, USA) at an error level of $\alpha=0.05$.

\section{Results}

\section{Chlorophyll breakdown}

Non-invasive, real-time in-situ determination of the relative chlorophyll degradation during banana ripening was measured with the DA-meter. The results, expressed as the $\mathrm{I}_{\mathrm{AD}}$-index, declined in line with the chlorophyll degradation, measured as decrease in chlorophyll reflection at $670 \mathrm{~nm}$. With ripening banana, values decreased from ca. 2.1 to $0.2 \mathrm{I}_{\mathrm{AD}}$ units (Fig. 3); this tenfold decline is ideal and very suitable for the identification of the current ripening stage 
Fig. 3 White calibration in counts and as percentage using the supplied barium sulphate disk (Color figure online)
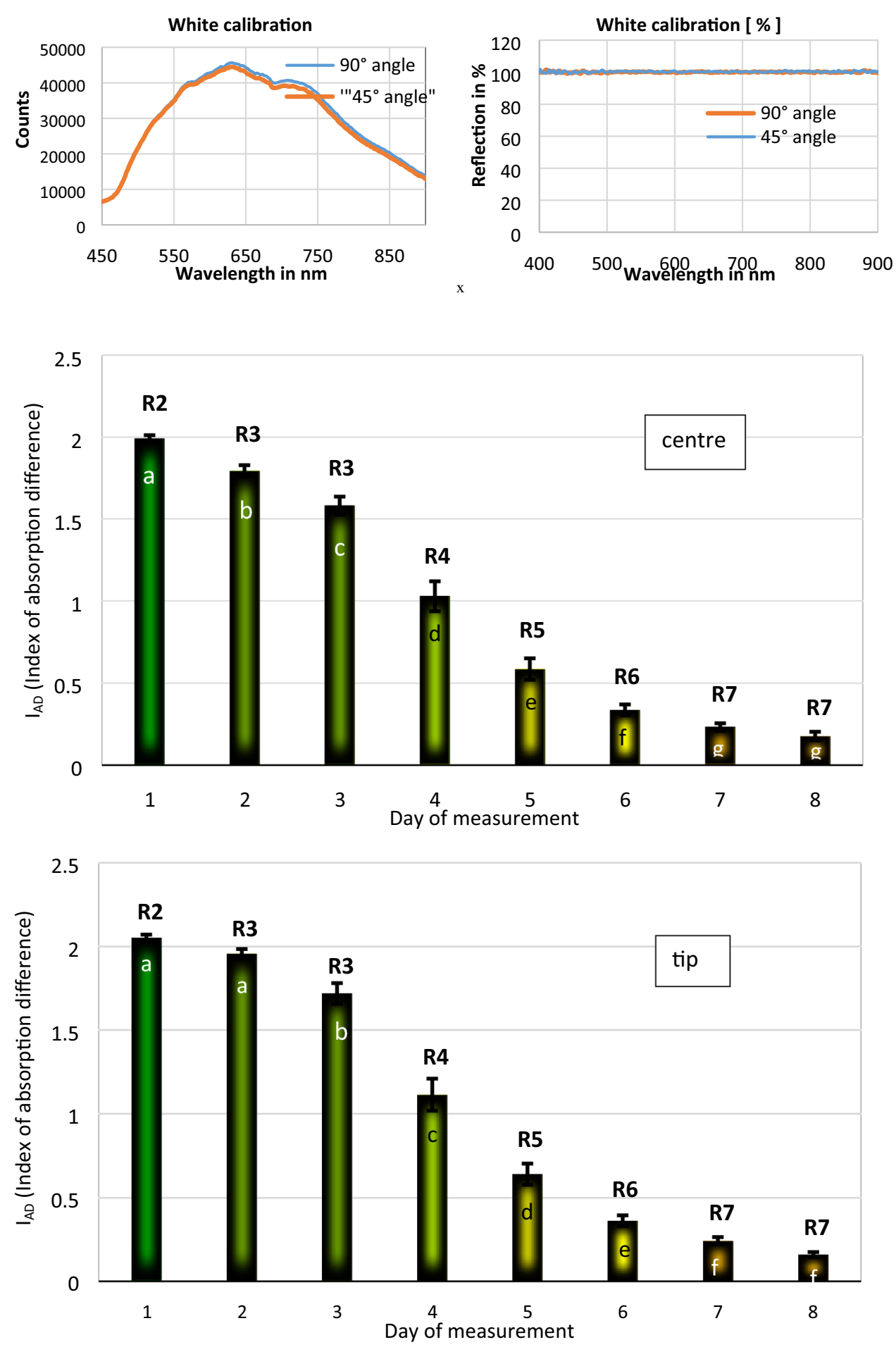

Fig. 4 Chlorophyll degradation in the peel centre (top) and tip (bottom) of banana during fruit maturation from $\mathrm{R} 2$ to $\mathrm{R} 7$, expressed as $\mathrm{I}_{\mathrm{AD}}$ (Index of Absorbance Difference), $( \pm \mathrm{SE}$, $\mathrm{n}=15$ bananas; 4 measurement spots per fruit, different letters denote statistical differences) (Color figure online)
(Table 2). Although not all ripening stages could be distinguished at the banana tip, significant differences (at $\alpha=0.05$ ) were detected between all ripening stages from R2 to R7 for the centre of the fruit (Fig. 4).

\section{Non-invasive assessment of changes in peel colour}

Banana ripening was associated with only one change in the CIE-Lab colour scheme. The b-values fluctuated between 56 and 72 from ripening stages $\mathrm{R} 2$ to $\mathrm{R} 7$, without differentiation of the ripening stages. However, CIE-LAB 
Table 2 Cluster formation based on IAD index of measurements taken on the fruit centre of banana fruit (DA-meter to distinguish ripening stages) for Fig. 4

\begin{tabular}{llll}
\hline Ripening stages & $\begin{array}{l}\text { IAD-index (confidence } \\
\text { interval 95\%) }\end{array}$ & Median & SE \\
\hline R2 & $2.03-1.95$ & 2.00 & 0.02 \\
R3 & $1.86-1.72$ & 1.8 & 0.03 \\
R4 & $1.22-0.83$ & 1.02 & 0.06 \\
R5 & $0.72-0.44$ & 0.59 & 0.09 \\
R6 & $0.40-0.26$ & 0.34 & 0.07 \\
R7 & $0.28-0.18$ & 0.23 & 0.03 \\
\hline
\end{tabular}

a values dramatically increased as indication of chlorophyll breakdown (Fig. 5a, b) and enable differentiation between all ripening stages R2 to R7. Similarly, colour angles declined from $98.7^{\circ}$ hue (R2), $97.3^{\circ}$ hue (R3), $92.7^{\circ}$ hue (R4), $89.4^{\circ}$ hue (R5); $87.5^{\circ}$ hue (R6) until $82.0^{\circ}$ hue (R7) at the fruit centre and from $99.7^{\circ}$ hue (R2), $98.3^{\circ}$ hue (R3), $92.9^{\circ}$ hue (R4), $89.6^{\circ}$ hue (R5), $87.5^{\circ}$ hue (R6) until $82.9^{\circ}$ hue (R7) close to the fruit tip (Fig. 5a, b).

\section{Spectral reflection of banana during ripening}

All ripening stages (unripe fruit stage $\mathrm{R} 3$ via the edible fruit stage R6 to overripe R7) were chosen for the noninvasive, real-time, in-situ measurement of the light reflection spectra. Therein, the first, short wave, trough at 487-497 $\mathrm{nm}$ changed relatively little during banana ripening (Fig. 6). By contrast, the chlorophyll peak viz trough at $673-683 \mathrm{~nm}$ was more pronounced with green banana than with yellow fruit. At the fruit tip, the yellow banana (R6) reflected more light (50-55\%) than the green fruit (R3) (20-50\%) (Fig. 6b) in line with the glossiness results (Fig. 7). By contrast, light reflection from the green banana exceeded that of the yellow banana at the fruit center above $712 \mathrm{~nm}$. The changes (disappearance) of the green chlorophyll trough at $673-683 \mathrm{~nm}$ were greater than those at the second trough at ca. $487-497 \mathrm{~nm}$; both troughs disappeared with ripening resulting in "flatter curves".
Figure 6 also shows the slower disappearance of the green chlorophyll trough at $673-683 \mathrm{~nm}$ at the tip relative to the fruit centre.

A new ripening index is suggested as depending on the troughs shown in Fig. 6 based on the first short wave trough at $494 \mathrm{~nm}$ and the chlorophyll absorbance at $679 \mathrm{~nm}$ and normalised (formula 1):

Banana ripening index $(B R I)=\frac{R 494+R 679}{10}$,

where $\mathrm{R} 494=$ light reflection at $494 \mathrm{~nm}$ and $\mathrm{R} 679=$ light reflection at $679 \mathrm{~nm}$.

The BRI values increased from 4.2 for unripe bananas (R3) to peak at 8.1 for ripe bananas (R6) and then decreased to 5.9 for over-ripe fruit based on the spectra and the particular two troughs for banana during ripening.

\section{Glossiness}

Figure 7 shows the development of glossiness during ripening from stage $\mathrm{R} 2$ (before entering the ripening room) to R7b (overripe, covered with brown spots) (Fig. 6) on both measuring spots on the banana fruit, centre and tip. The degree of glossiness increased from stage R2 (dark green) to stage R7a (yellow with brown spots) in both the centre (Fig. 6a) and the tip of the banana (Fig. 7b). The values for glossiness of the tip ranged between ca. to 120 a.i. to 186 a.i. during fruit maturation compared with the centre with values of 150 a.i. and 220 a.i. The wider range of glossiness values indicates the centre as a better point for maturity assessment. Furthermore, the centre of the fruit was chosen for the subsequent non-invasive evaluation of glossiness during banana maturation, because of its easy access and a less curved surface. The measurement is non-invasive, real-time and affordable. The banana fruit showed a peak in glossiness at its stage of most advanced ripeness when the fruit is yellow (Fig. 7) just before senescence. To exclude any colour response of the glossiness sensor, printed charts of the same colour as the ripening banana were measured with the sensor. The results in Fig. 8 showed that yellow was associated with the smallest values, while green and brown showed larger values. This is in an opposite way to Fig. 7,
Fig. 5 Changes in peel colour in (a) the centre of the banana fruit and (b) close to the tip of the banana fruit measured as $a$ - and $b$-values (continuous lines) in the CIE-Lab colour scheme and converted to hue values $( \pm \mathrm{SE})$ $(\mathrm{n}=15$ bananas per ripening stage) (Color figure online)
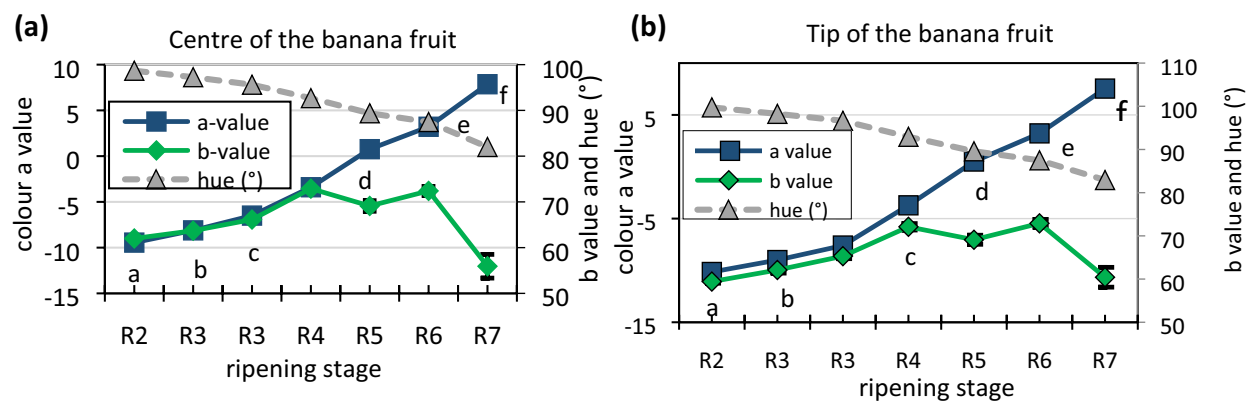

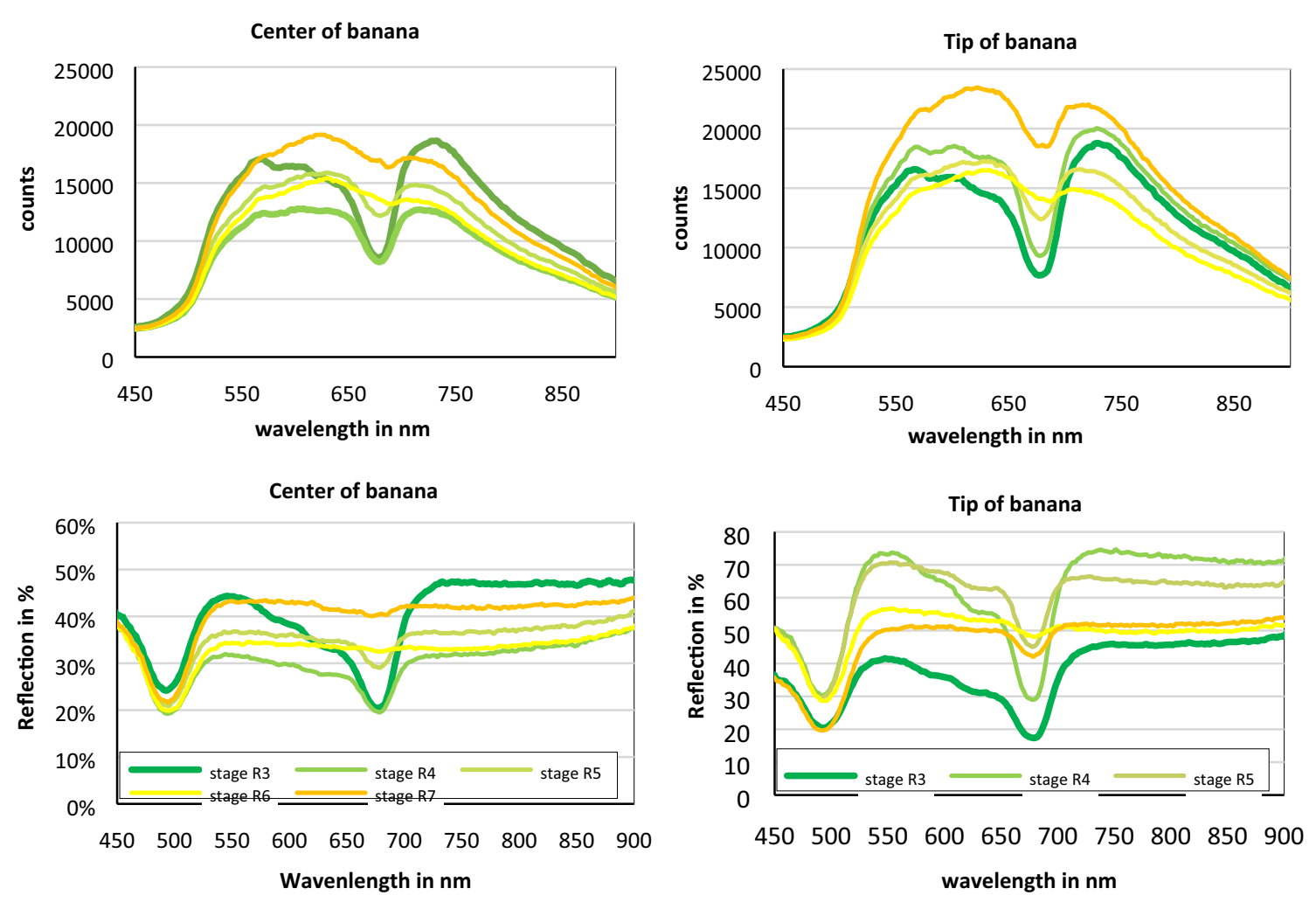

Fig. 6 a Spectral reflection (top) and b percentage reflection after division by the white calibration (bottom) of banana fruits (R3-R7) showing (i) the greater changes (disappearance) of the green chlo-

where the largest glossiness values were at the yellow stage (R7) and lower values in both immature green (R2-3) and yellow-brown overripe stages (R7).

\section{Starch degradation}

Figure 9 shows the starch breakdown using cross-sections of the bananas obtained in the centre of the fruit in relation to the ripening stage. The starch breakdown started from the core of the pulp, the placenta and endocarp with the starch remaining longest during maturation in the mesocarp. The diagram also visualises the shrinkage of the peel/skin (Fig. 9).

\section{Water displacement from peel to pulp}

During ripening, water is eventually translocated from the peel, which contains the vascular tissues (xylem), to the pulp. Peel of immature banana maintained its water content at $90.5 \%$ fresh mass until stage R5. Thereafter, the water content of the peel dropped from 90.5 to $82.9 \%$ fresh mass (FM), hence ca. $7.6 \%$ is translocated from the peel to the pulp by the end of maturation at stage R7 (Fig. 10). The apparent discrepancy between ca. $7.6 \%$ decline in rophyll trough at $673-683 \mathrm{~nm}$ than the smaller changes at the short wave trough at $487-497 \mathrm{~nm}$ and (ii) the flattening of the curves with ripening (Color figure online)

water content of the banana peel, but only $2 \%$ increase in water content in the pulp between R3 and R7 can be possibly explained by fruit transpiration, as transpiration is only possible from the fruit peel but not the pulp and the stalk/pedicel is dried.

Concomitant measurements of mass loss during this ripening period showed a mass, largely water loss, which declined from $8 \mathrm{~g} /$ fruit/day at stage $\mathrm{R} 3$ to $2 \mathrm{~g} /$ fruit/day at stage R7 measured at room temperature (results not shown). The $7.6 \%$ (FM) water displacement at R7 is equivalent to $8.4-10 \mathrm{~g}$ water, in relation to $3-8 \mathrm{~g}$ weight loss (Fig. 11b), which is largely transpiration.

\section{Fruit firmness}

Water displacement from the peel to the pulp is one of the major causes of the loss in peel firmness during banana ripening. The softening, which makes the banana edible, was associated with a decline in firmness from 82 Shore at stage R2 (green) to 42 Shore at stage R7 (overripe) (Fig. 12) measured with the penetrometer at the centre of the banana fruit. 
Fig. 7 Increase in glossiness, a measured in the centre of the fruit from ripeness stage 3 to stage $7( \pm$ SE) $(n=20$; 4 measurement spots per fruit) (top) and $\mathbf{b}$ measured close to the tip of the fruit from ripeness stage 3 to stage $7( \pm S E)(n=20$ bananas; 4 measurement spots per fruit) (bottom) (Color figure online)
Fig. 8 Response of the luster sensor to colour variation, using paint colour mixing charts (from a hardware store) in the same colours as of ripening banana $( \pm \operatorname{SE})(n=10)$ (Color figure online)
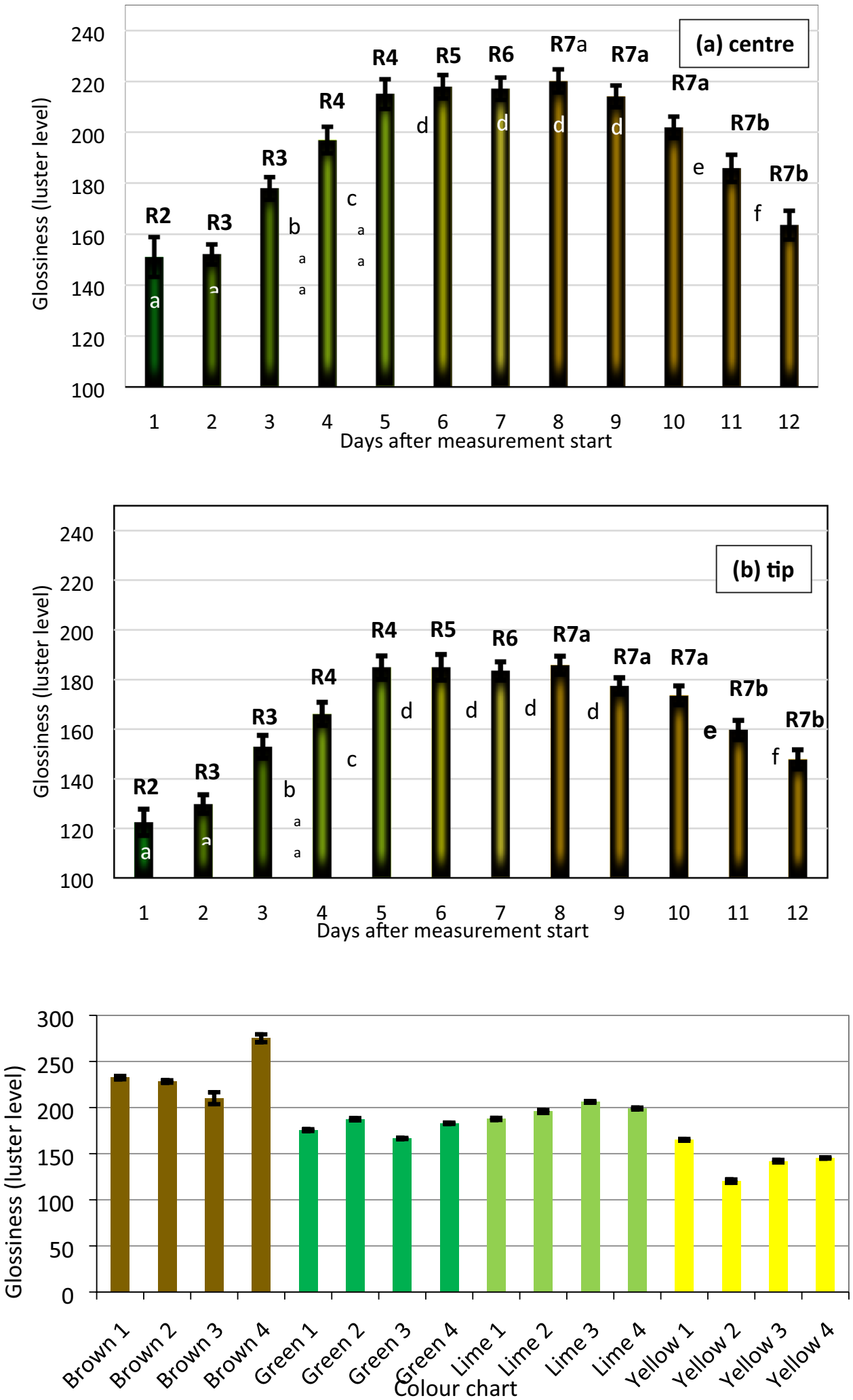

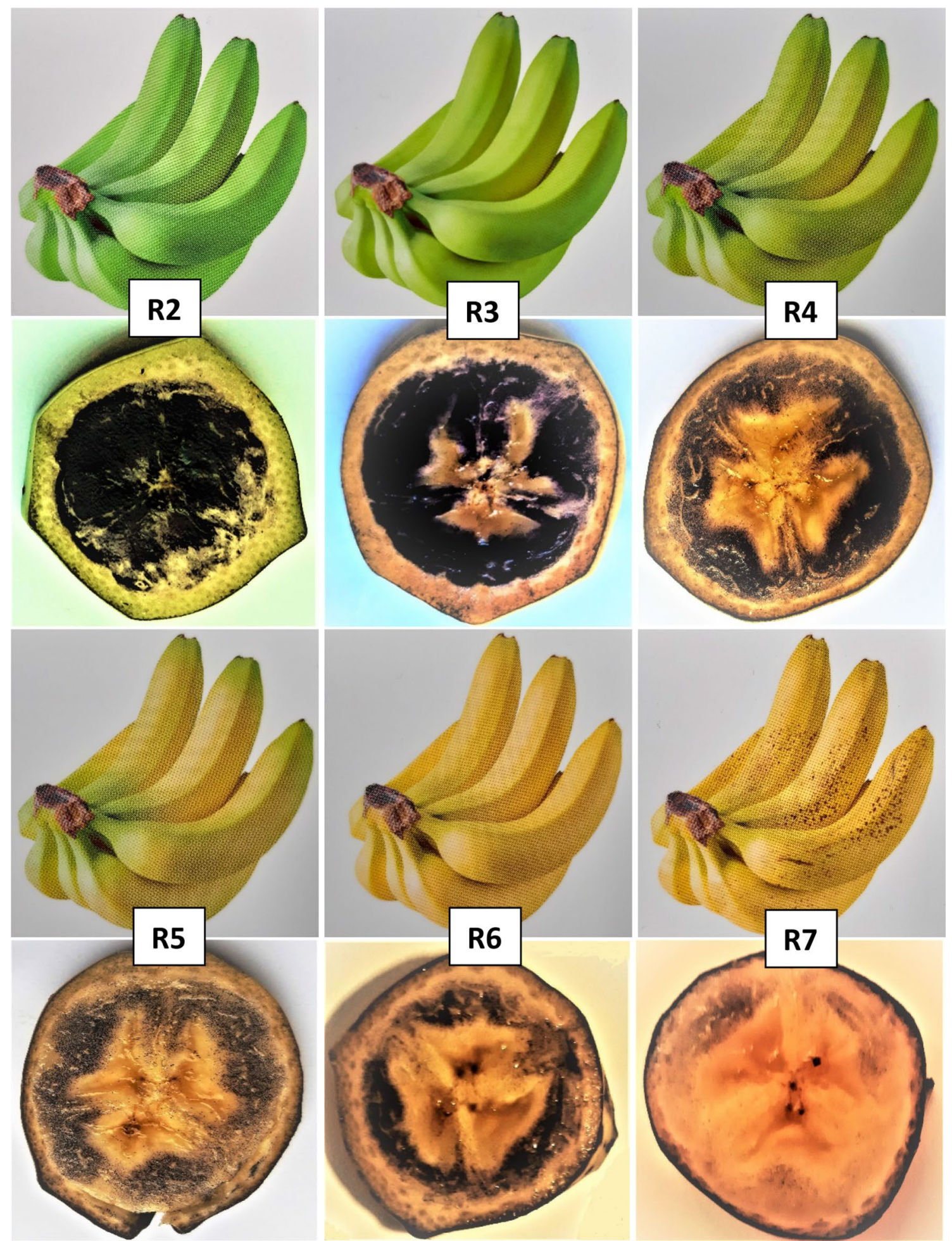

Fig. 9 Starch breakdown of cross-sections of Cavendish banana to identify the ripening stage from R2 (green) to R7 (overripe) (Color figure online)

\section{Discussion}

The objective of the present work was to compare a wide variety of non-invasive, real time, on-site and affordable technologies as to their suitability to identify the ripeness stage of banana fruit either during or before entering the 


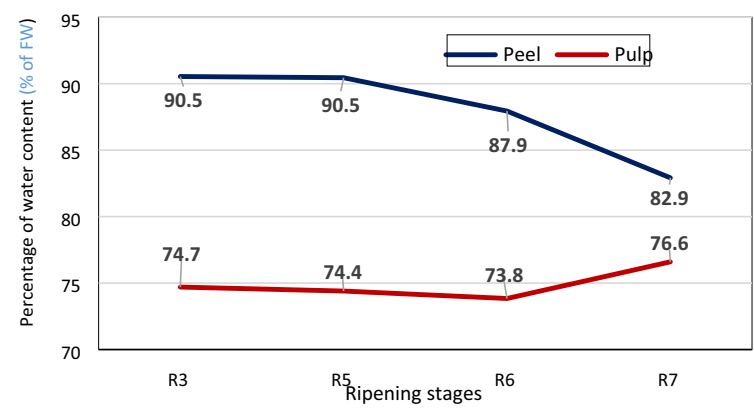

Fig. 10 Change of water contents in peel and pulp of banana fruit during ripening showing the water loss in the peel and increase pulp water resulting in translocation of water from the peel to the pulp (without transpiration and water loss) (from ripening stage R5 to R7) $(n=4$ bananas per ripening stage) (Color figure online)

Changes in banana weight during ripening

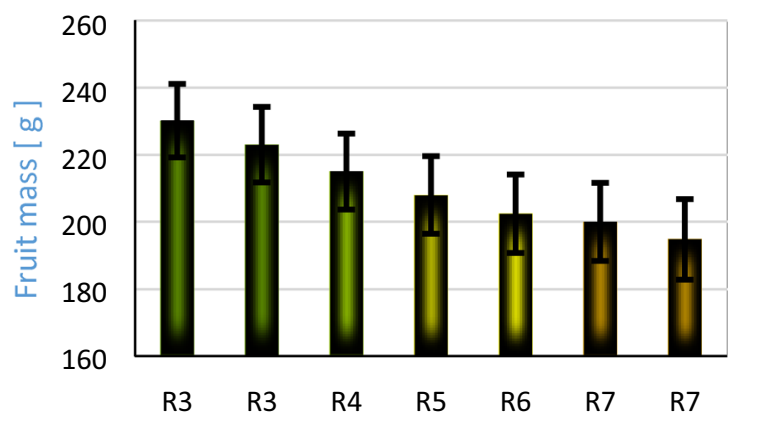

ripening room or in retail or both and aid the ripening facility to determine the target ripening stage.

\section{Chlorophyll breakdown and DA-meter}

In banana, the colour change from green to yellow is a gradual process starting from the ends of the curved fruit. The degradation of chlorophyll a (and to a lesser extent, chlorophyll b) is brought about by the enzyme chlorophyllase; its activity increases during maturation with a concomitant increase in a- and B-carotene [10].

The results of the DA-meter (Fig. 3) including all the ripening stages from $\mathrm{R} 2$ to $\mathrm{R} 7$ are two-fold larger $\left(\mathrm{I}_{\mathrm{AD}}=0-2.2\right)$ in comparison to Hashim et al. [1], who reported a similar slope but considerably smaller values $\left(\mathrm{I}_{\mathrm{AD}}=0-1\right)$. However, the DA-meter readings $\left(\mathrm{I}_{\mathrm{AD}}\right.$-index $)$ proved as one of

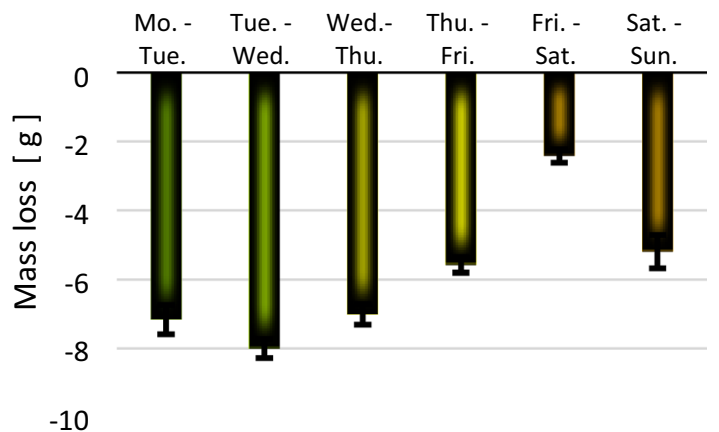

Fig. 11 a Changes in banana weight and $\mathbf{b}$ weight loss of bananas during ripening, as a possible indication of relative changes in transpiration $( \pm$ SE) $(n=5)$ (Color figure online)

Fig. 12 Decline in peel firmness in the centre of banana fruit from the ripening room $( \pm S E)$ $(\mathrm{n}=15$ bananas; one measurement spot per fruit) (Color figure online)

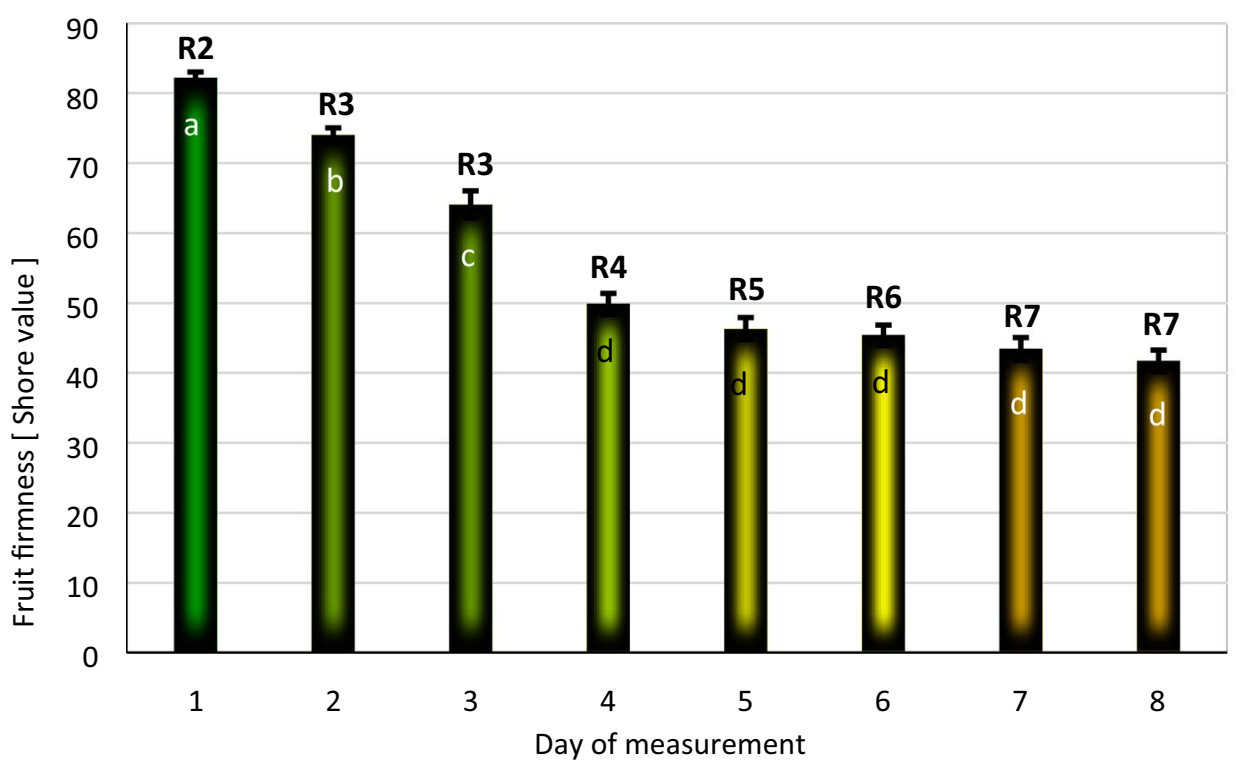


Table 3 Changes associated with ripening in banana pulp and peel (for refs please see text)

\begin{tabular}{lll}
\hline Tissue & Peel & Pulp \\
\hline $\begin{array}{l}\text { Changes in colour, chlo- } \\
\text { rophyll and carbohy- } \\
\text { drates }\end{array}$ & $\begin{array}{l}\text { loss of green colour due to chlorophyll degradation } \\
\text { increase in a- and ß-carotene }\end{array}$ & $\begin{array}{l}\text { Decrease in acidity and conversion of starch to sugar } \\
\text { Accumulation of glucose and fructose }\end{array}$ \\
$\begin{array}{l}\text { Water relations, osmotic } \\
\text { pressure and tissue } \\
\text { softening }\end{array}$ & Transpiration and water displacement from peel to pulp & $\begin{array}{l}\text {...leading to an increase in osmotic potential, con- } \\
\text { tains vascular bundles } \\
\text { Loss in turgor pressure, tissue softening. }\end{array}$ \\
\hline
\end{tabular}

the suitable parameters to distinguish between all ripening stages R2-R7, irrespective of the measured position (centre and tip) (Table 3).

\section{Colour change and colourimeter}

Our a colour values in the range of -15 to +10 and our $b$ colour values in range of 50 to 80 are similar but somehow larger than the values of -20 to 0 (a value) and 35 to 57 (b value) of Juncai et al. [11] over the same ripening stages; in both cases the a values continuously increased and the $\mathrm{b}$ values increased from R2 to R5 and dropped from R6 to R7. Juncai et al. [11] found a, b or L values alone insignificant to determine the banana ripening stage, while we propose solely the a CIE-Lab colour value (Fig. 4) as sufficient to distinguish the ripening stage of the banana fruit and the $\mathrm{L}$ and $b$ value also insufficient.

\section{Spectrometry}

The recorded light reflection curves (Fig. 6) are in line with those of Rajkumar et al. [12]. In their light reflection study, authors also observed the two troughs in the spectrum at ca. $490 \mathrm{~nm}$ and $680 \mathrm{~nm}$; the spectral reflectance at the chlorophyll absorption peak around $680 \mathrm{~nm}$ increased from $10 \%$ at ripening stage $\mathrm{R} 1$ to peak with $50 \%$ at stage $\mathrm{R} 3$ and subsequently decreased back to $15 \%$ at stage R6.

\section{Biochemical changes associated with fruit maturation- conversion of starch to sugar}

Changes during banana ripening (Table 3) are associated with (a) a conversion of starch into sugar [13, 14], (b) an increase in osmotic potential in the pulp due to an increase in reducing sugars (glucose and fructose) from 0.31 to $14.7 \%$ [10], and (c) a subsequent loss in turgor pressure in the peel cells and (d) water displacement from banana peel to pulp as a cause of fruit softening [15].

\section{Water displacement from peel to pulp}

Our water contents values of the pulp for ripening stages R2 until R7 of 74.7 to $76.6 \%$ (w/w) (Fig. 9) compare favourably with 72.5 to $76.5 \%$ from R1 until R7 of Ward and Nussinovitch [4]. These increases in water content of the pulp viz. losses in water content of the peel are due to both the transpiration of the peel to the atmosphere and water displacement from the peel to the pulp e.g. by changes in the osmotic potential due to starch breakdown into sugars [16], thereby contributing to an increase in the fresh weight of the pulp as the fruit ripens. Hence, the pulp to peel mass ratio increased during ripening [17]. Concomitant measurements showed 3-6 g/day weight loss for a ca. $200 \mathrm{~g}$ banana fruit (Fig. 10), equivalent to $1.5-3 \%$ water loss. To our knowledge, the values in Fig. 9 for water displacement and transpiration have not been reported in the literature before.

\section{Comparison of the suitability of the methods under investigation}

Our study has shown, for the first time, based on a comparative approach, the differentiation between all ripening stages of banana fruit in case of DA-meter, colourimeter and spectrometer. Hence, we propose a combination of the colourimeter, spectrometer (banana ripening index) and the DA-meter (Fig. 4). The other two methods, the luster sensor and the penetrometer, were found useful to distinguish between three but not all ripening stage (Table 4). Hence, the individual data are not discussed with those obtained previously.

Possible applications include the DA-meter method, the colourimeter method and the spectrometer method, i.e. methods based on reflection of visible light (Fig. 13).

Table 4 Comparison of non-invasive, real-time, on-site employed methods for the differentiation of the banana ripening stages at the fruit centre

\begin{tabular}{llllll}
\hline Ripening stage/method & R2-R3 & R3-R4 & R4-R5 & R5-R6 & R6-R7 \\
\hline Luster sensor & & v & v & & \\
DA Meter-IAD index & v & v & v & v & v \\
Colourimeter & v & v & v & v & v \\
Spectrometer (BRI) & v & v & v & v & v \\
Penetrometer & v & v & & & \\
\hline
\end{tabular}


Fig. 13 Comparison of the three selected non-invasive real-time, in-situ technologies to determine the ripening stage of banana $( \pm \mathrm{SE})$ (Color figure online)
Centre of the banana fruit

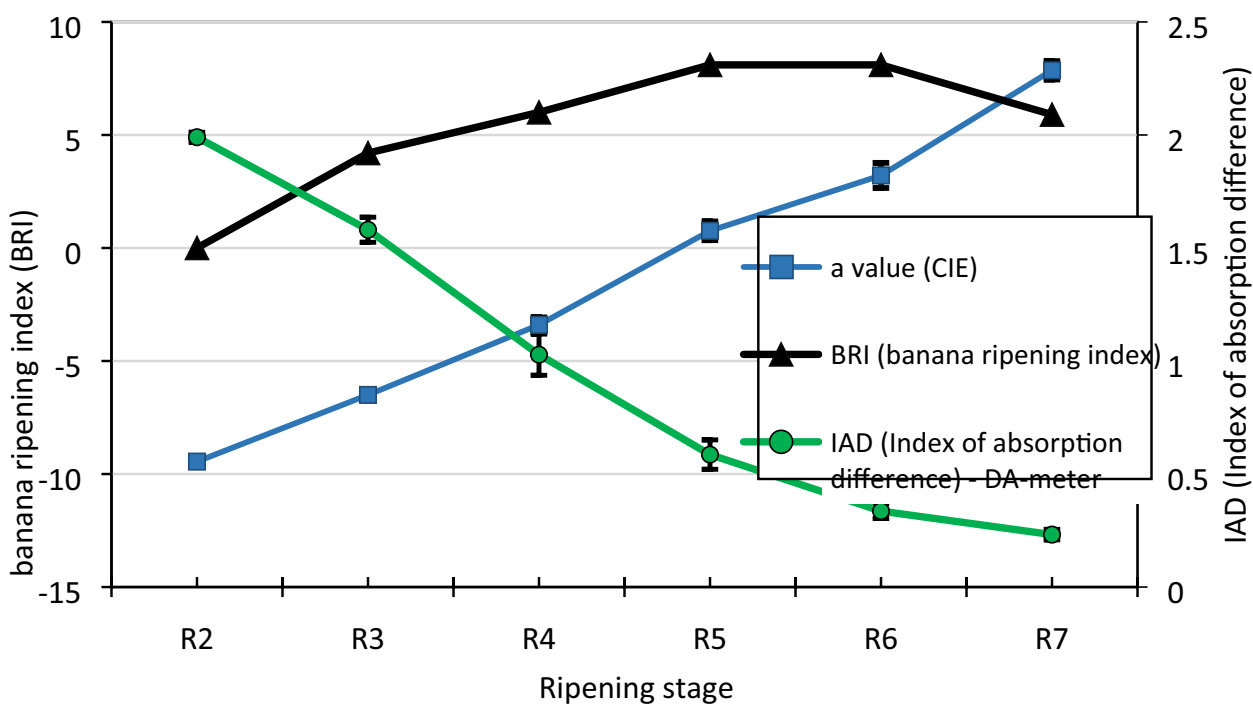

Currently, technology is underway to develop sensors (e.g. Phazir) for the detection of either water or dry content non-destructively using their respective absorption bands in the NIR range such as $975 \mathrm{~nm}[12,18,19]$.

\section{Conclusions and outlook}

Our study has shown, for the first time, based on a comparative approach of six non-invasive, real time devices, the differentiation between all ripening stages of banana fruit in case of DA-meter, colourimeter and spectrometer. The luster sensor and the penetrometer distinguished some, but not all ripening stages and are therefore appropriate only to separate and identify these stages. For the precise identification of all ripening stages of banana, we hence, propose a combination of the colourimeter, spectrometer (banana ripening index) and the DA-meter (Table 4) using the centre of the fruit as measuring position and the novel BRI as decision support, particularly for banana ripening, where it is most needed.

Differences in the predicted green life can be used to prioritize containers for unloading in the discharge port or to implement quality-based warehouse management strategies; containers, which arrive at the ripening rooms before their green life ends, can be re-routed, in addition to the present, colour-based ripening scale.

Acknowledgements We thank the Walter Pott GmbH Fruchtimport Bananenreifereien, Leverkusen for providing freshly shipped banana samples before and after entering the ripening rooms, Achim Kunz for support with the colourimeter, Sebastian Bell for spectra acquisition, Gertrudis Heimes for help with the potassium iodine staining, Dr Peter Buch, DLR Bad Godesberg for expert advice on the physical issues and
Frederik Henn for the revision of the English language and Dr John Robinson for sparking off the interest on bananas during the sabbatical of the senior author in the 90s in Natal, South Africa.

Funding Open Access funding enabled and organized by Projekt DEAL.

\section{Declarations}

Conflict of interest Authors declare no conflict of interest.

Open Access This article is licensed under a Creative Commons Attribution 4.0 International License, which permits use, sharing, adaptation, distribution and reproduction in any medium or format, as long as you give appropriate credit to the original author(s) and the source, provide a link to the Creative Commons licence, and indicate if changes were made. The images or other third party material in this article are included in the article's Creative Commons licence, unless indicated otherwise in a credit line to the material. If material is not included in the article's Creative Commons licence and your intended use is not permitted by statutory regulation or exceeds the permitted use, you will need to obtain permission directly from the copyright holder. To view a copy of this licence, visit http://creativecommons.org/licenses/by/4.0/.

\section{References}

1. N. Hashim, S.E. Adebayo, K. Abdan, M. Hanafi, Comparative study of transform-based image texture analysis for the evaluation of banana quality using an optical backscattering system. Postharvest. Biol. Technol. 135, 38-50 (2018)

2. P.M. Kotecha, B.B. Desai, Bananas, in Handbook of Fruit Science and Technology: Production, Composition, Storage and Processing. ed. by D.K. Salunkhe (Taylor \& Francis, Abington, 1995), pp. 67-88

3. K.L. Yam, S.P. Papadakis, A simple digital imaging method for measuring and analysing colour of food surfaces. J. Food Eng. 61, 137-142 (2003) 
4. G. Ward, A. Nussinovitch, Peel gloss as a potential indicator of banana ripeness. LWT Food Sci. Technol. 29, 289-294 (1996)

5. T. Ringer, L. Damerow, M. Blanke, Non-invasive differentiation of surface features of banana during ripening. J. Food Sci. Technol. 55(10), 4197-4203 (2018). https://doi.org/10.1007/ s13197-018-3352-2

6. L. Peiffer, S. Ottnad, A. Kunz, L. Damerow, M. Blanke, Mechanical thinning in apple improves fruit quality, assessed by the DA-meter. Sci. Hortic. 233, 526-531 (2018). https://doi. org/10.1016/j.scienta.2017.11.011

7. P. Jaiswal, S.N. Jha, P.P. Kaur, Prediction of textural attributes using color values of banana (Musa sapientum) during ripening. J. Food Sci. Technol. 51(6), 1179-1184 (2012)

8. R.G. McGuire, Reporting of objective colour measurements. HortScience 27(12), 1254-1255 (1992)

9. M. Schüsseler, L. Damerow, M. Blanke, Effect of colouration on non-invasive russet detection on pome fruit. Postharvest. Biol. Technol. 152(1), 54-59 (2019). https://doi.org/10.1016/j.posth arvbio.2019.02.016

10. E.E. Finney, I. Ben-Gera, D.R. Massie, An objective evaluation of changes in firmness of ripening bananas using a sonic technique. J. Food Sci. 32(6), 642-647 (1967)

11. H. Juncai, H. Yaohua, H. Lixia, G. Kangquan, T. Satake, Classification of ripening stages of bananas based on support vector machine. Int. J. Ag. Biol. Eng. 8(6), 99-103 (2015)

12. P. Rajkumar, N. Wang, G. Eimasry, G.S.V. Raghavan, Y. Gariepy, Studies on banana fruit quality and maturity stages using hyperspectral imaging. J. Food Eng. 108, 194-200 (2011)

13. R.B.H. Willis, J.B.K. Lim, H. Greenfield, Changes in chemical composition of Cavendish banana (Musa acuminata) during ripening. J. Food Biochem. 8, 69-77 (1984)
14. C.K. Reddy, S. Haripriya, P.V. Vidya, Morphology, physicochemical and functional characteristics of starches from different banana cultivars. J. Food Sci. Technol. 52(11), 7289-7296 (2015)

15. M.H. Williams, M. Vesk, M.G. Mullins, A scanning electron microscope study of the formation and surface characteristics of the peel of the banana fruit during its development. Bot. Gaz. 150, 30-40 (1989)

16. R.H. Stover, N.W. Simmonds, Banana (3rd edn), in Routine PostHarvest Screening of Banana/Plantain Hybrids: Criteria and Methods. INIBAP Technical Guidelines 2. Rome, Italy. ed. By B.K. Dadzie, J.E. Orchard (Wiley, New York, 1987), p. 468

17. B.K. Dadzie, J.E. Orchard, Routine Post-Harvest Screening of Banana/Plantain Hybrids: Criteria and Methods. INIBAP Technical Guidelines 2. Rome, Italy (1997).

18. B. Althaus, M. Blanke, Non-destructive, opto-electronic evaluation of freshness and shrivel of Bell pepper fruit. J. Imaging 6 , 122 (2020). https://doi.org/10.3390/jimaging6110122

19. T. Pügner, J. Knobbe, H. Grüger, Near-infrared grating spectrometer for mobile phone applications. Appl. Spectrosc. 70(5), 734-735 (2016)

Publisher's Note Springer Nature remains neutral with regard to jurisdictional claims in published maps and institutional affiliations. 